\title{
Feasibility Studies on Underwater Laser Surface Hardening Process
}

\author{
Biao Jin, Min Li, TaeWoo Hwang, and YoungHoon Moon \\ School of Mechanical Engineering, Engineering Research Center for Net Shape and Die Manufacturing, \\ Pusan National University, Busan 609-735, Republic of Korea
}

Correspondence should be addressed to YoungHoon Moon; yhmoon@pusan.ac.kr

Received 28 November 2014; Revised 23 March 2015; Accepted 30 March 2015

Academic Editor: Simo-Pekka Hannula

Copyright (C) 2015 Biao Jin et al. This is an open access article distributed under the Creative Commons Attribution License, which permits unrestricted use, distribution, and reproduction in any medium, provided the original work is properly cited.

Laser surface hardening process is a very promising hardening method for ferrous and nonferrous alloys where transformations occur during cooling after laser melting in the solid state. This study experimentally characterizes laser surface hardening of tool steel in both water and air. For the underwater operation, laser surface scanning is performed over the tool steel surface which is immersed in water. The laser surface hardening tests are performed with a maximum $200 \mathrm{~W}$ fiber laser with a Gaussian distribution of energy in the beam. For the surface hardening, single-track melting experiment which sequentially scans elongated path of single line has been performed. As the hardened depth depends on the thermal conductivity of the material, the surface temperature and the penetration depth may be varied by underwater laser processing. The feasibility of underwater laser surface hardening process is discussed on the basis of average hardness level and hardened bead shape.

\section{Introduction}

Lasers have been used in a number of ways to modify the properties of metal surfaces. The most often objective of the laser processing has been to harden the surface in order to provide increased wear resistance [1-4]. The laser beam irradiates the metal surface and causes very rapid heating of a thin layer of material near the surface. When the beam moves along the surface, the local heat deposited in the thin layer will quickly be conducted away, and the heated area cools rapidly. This is basically self-quenching process of the surface region $[5,6]$. Certain metals, notably carbon steel, may undergo transformation hardening by heating followed by rapid cooling $[7,8]$. This process yields a locally hardened surface. The hardened depth depends on the thermal conductivity of the material. The surface temperature and the penetration depth may be varied by adjusting the laser power, the surface scan speed, and the focusing of the beam. Greater hardening depths may be obtained by slow scan rate and larger laser power. Laser hardening is suitable for applications that require high hardness with relatively shallow case depth on selected surface areas, with no geometrical distortion [9$11]$.
It can be used for geometries with irregular shapes, grooves, lines, and gear teeth. The automotive industry, in which wear resistance on selected surfaces is desired, has been the most important application area for laser hardening.

As the hardened depth depends on the thermal conductivity of the material, the surface temperature and the penetration depth may be varied by underwater laser processing $[12,13]$.

This study experimentally characterizes laser surface hardening of tool steel in both water and air. For the underwater operation, single line laser surface scanning is performed over the tool steel surface which is immersion in water. Underwater effects on laser surface hardening process are estimated and discussed on the basis of average hardness level, melted bead shape, and width of heat affected zone in hardened layer.

\section{Experimental}

2.1. Materials. Specimen used in this study is AISI D2 cold worked tool steel. AISI D2 is a high-Cr, high-C tool steel alloyed with Mo and V. Chemical compositions of AISI D2 steel are shown in Table 1. 


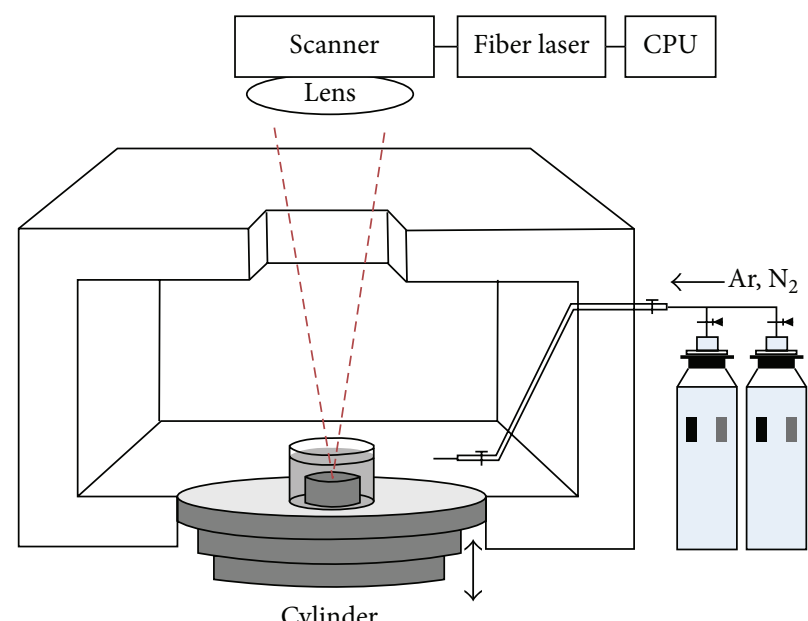

Figure 1: Schematic drawing of direct laser hardening system.

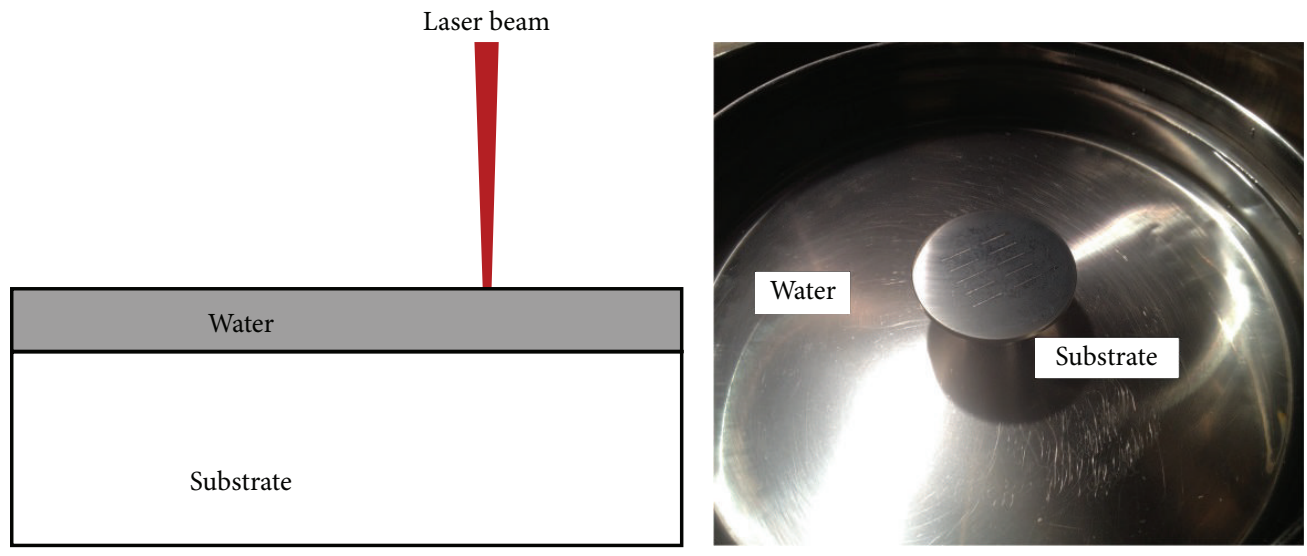

FIGURE 2: Immersed specimen for underwater experiment.

TABLE 1: Chemical compositions of AISI D2 steel.

\begin{tabular}{lccccccc}
\hline Element & $\mathrm{Fe}$ & $\mathrm{Cr}$ & $\mathrm{C}$ & $\mathrm{Mo}$ & $\mathrm{Mn}$ & $\mathrm{V}$ & $\mathrm{Si}$ \\
\hline wt.\% & Bal. & 12.10 & 1.50 & 1.00 & 0.45 & 0.35 & 0.25 \\
\hline
\end{tabular}

TABLE 2: Experimental conditions for the direct laser hardening.

\begin{tabular}{lcc}
\hline Test condition & Laser power $(\mathrm{W})$ & Scan rate $(\mathrm{mm} / \mathrm{s})$ \\
\hline $\begin{array}{l}\text { Ar environment, } \\
\text { underwater }\end{array}$ & $100,150,200$ & $7.32 \sim 21.96$ \\
\hline
\end{tabular}

2.2. Equipment. Figure 1 schematically shows the direct laser hardening system. The source of radiation is a fiber laser (IPG YLR-200) produced by IPG Photonics with a maximum power of $200 \mathrm{~W}$, wave length of $1.07 \mu \mathrm{m}$, and a laser beam diameter of $0.08 \mathrm{~mm}$ in the focal position. A scanner (SCANLAB hurrySCAN 20) was used to control the laser scanning method. The chamber was filled by argon gas in all experiments. The vertical movement of the cylinder was driven by a motor. The experimental conditions for the laser hardening are shown in Table 2.

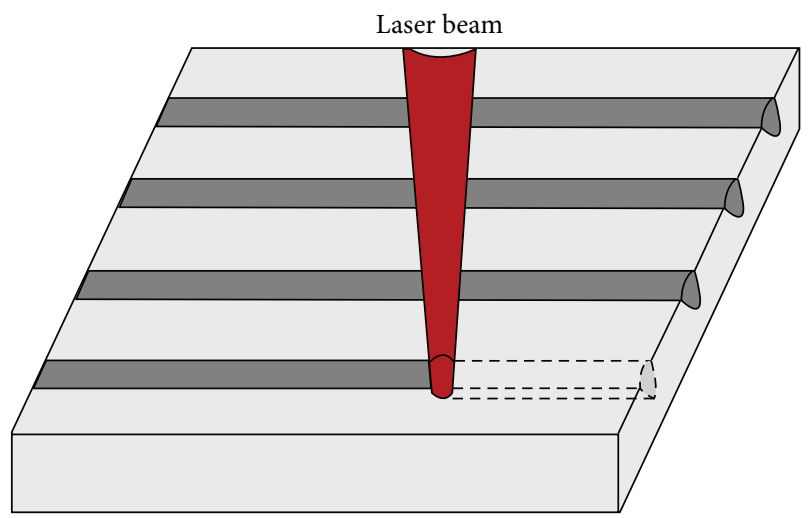

FIGURE 3: Schematic drawing of single-track laser melting experiment.

For the underwater surface hardening experiment, the sample is immersed in distilled water of $25^{\circ} \mathrm{C}$ during the laser hardening, as shown in Figure 2. The sample with water was placed in a cylindrical container. Through the series of preliminary tests in a given laser hardening system, 


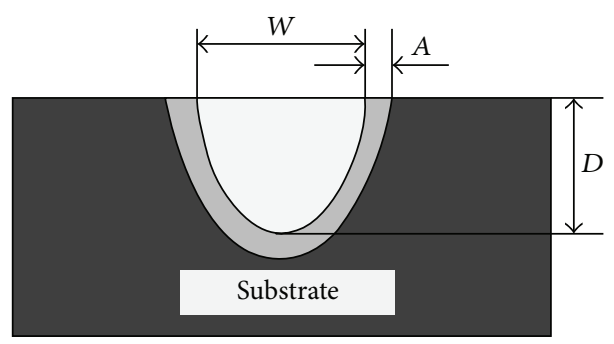

FIGURE 4: Schematic drawings of cross-sectional bead geometry.

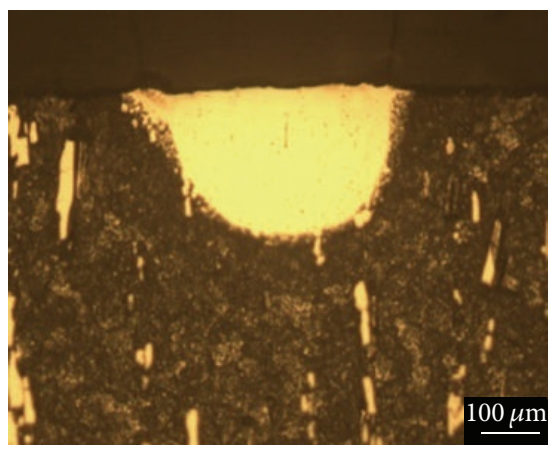

(a)

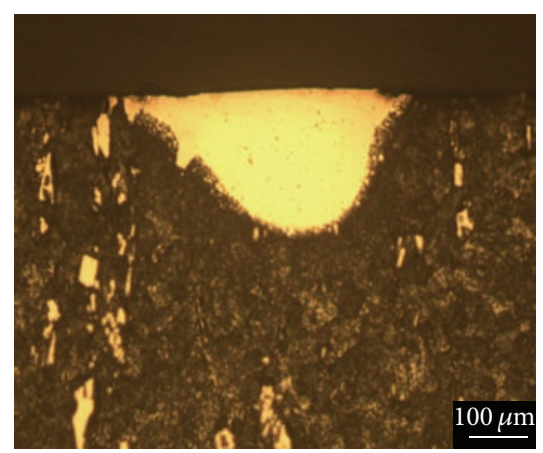

(b)

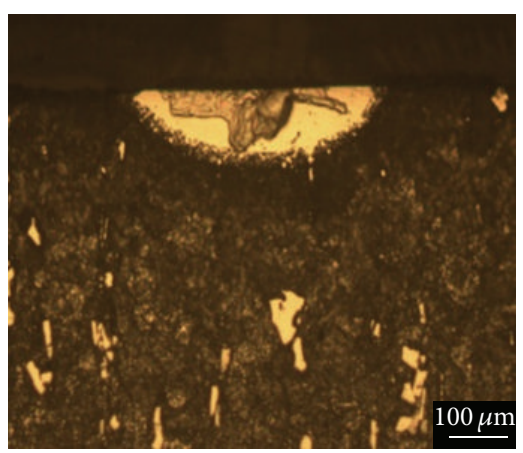

(c)

FIGURE 5: Cross-sectional views of a single-line bead hardened at Ar environment. Scanning rates are (a) $7.32 \mathrm{~mm} / \mathrm{s}$, (b) $14.64 \mathrm{~mm} / \mathrm{s}$, and (c) $21.96 \mathrm{~mm} / \mathrm{sec}$. Laser power is constant $(150 \mathrm{~W})$.

the water layer above the sample surface is set to be $1 \mathrm{~mm}$. For the comparison purpose, the laser forming in air is also investigated. The distance between the lens and the sample was kept constant during all experiments.

In order to understand the effects of the process parameters such as laser power and scan rate, on the laser hardening behaviors, a series of experiments were conducted. The component properties are strongly influenced by the molten pool size, which is mainly controlled by the laser energy input. For the surface hardening, single-track melting experiment which sequentially scans elongated path of single line has been performed at various laser processing parameters, as shown in Figure 3.

For the analysis of underwater effects on laser surface hardening process, average hardness level, shape of hardened bead, and width of heat affected zone have been analyzed. Hardness values were measured at hardened layer, HAZ, and base metal, respectively, and averaged.

For the analysis of shape of hardened bead and width of heat affected zone, the bead shape in hardened zone was classified by three geometrical variables: penetration depth into the substrate $(D)$, deposition width $(W)$, and HAZ width $(A)$ as shown in Figure 4.

\section{Results and Discussion}

When the beam moves on, the surface will cool extremely rapidly because of thermal conduction of the heat energy from the thin heated layer into the interior of the metal. This leads to transformation hardening of the areas that the laser beam has traversed. To estimate the underwater effects on laser surface hardening process, shape of hardened bead and average hardness level have been analyzed.

To study the underwater effects on shape of hardened bead, single line beads were produced at different scan rates ranging from $7.32 \mathrm{~mm} / \mathrm{s}, 14.64 \mathrm{~mm} / \mathrm{s}$, and $21.96 \mathrm{~mm} / \mathrm{s}$, respectively.

Figure 5 shows cross-sectional views of single line beads hardened at Ar environment with different scan rates.

The deposition line width, the penetration depth, and HAZ width have a strong dependence on scan rate. An increase in the scan rate decreases the line width, the penetration depth, and HAZ width, since an increase in speed decreases the melting depth as a consequence of the shorter interaction time. In addition, the thermal gradient does not allow sufficient time for the molten metal to penetrate deeply into the substrate. Figure 6 shows cross-sectional views of single line beads hardened at underwater condition with different scan rates.

The effects of scan rates on shape of hardened bead are somewhat similar, but the penetration depth and HAZ width are significantly smaller than those of Ar environment shown in Figure 7. This is mainly due to the refraction of the beam in water layer, as shown in Figure 8. The laser spot diameter was changed from $430 \mu \mathrm{m}$ to $380 \mu \mathrm{m}$ at $1 \mathrm{~mm}$ water layer. Furthermore, the accelerated heat dissipation along water layer decreases the melting depth as a consequence of the shorter interaction time.

Figure 9 compares the hardness for underwater condition with those for Ar environment as a function of scan rates. 


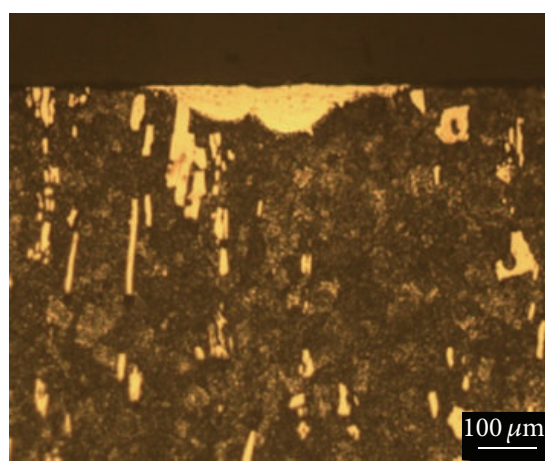

(a)

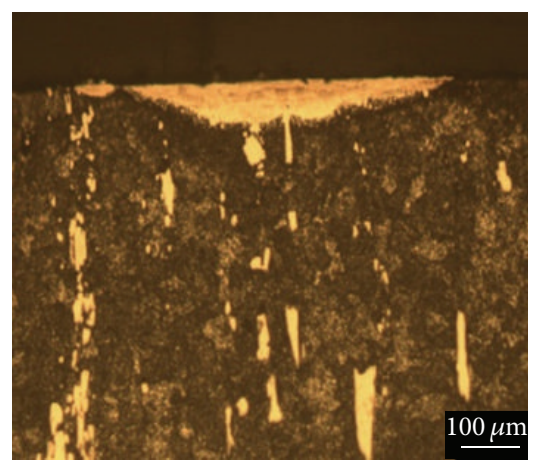

(b)

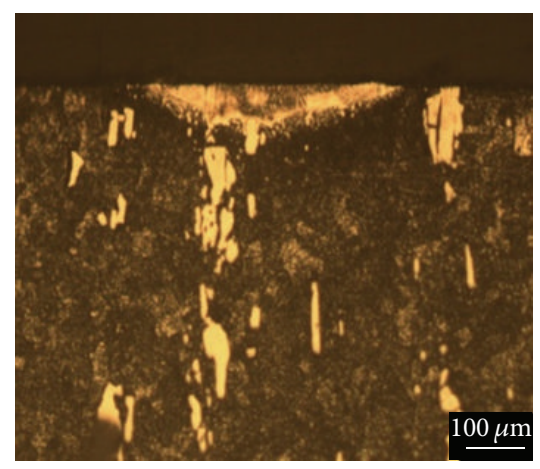

(c)

Figure 6: Cross-sectional views of a single-line bead hardened at underwater condition. Scanning rates are (a) $7.32 \mathrm{~mm} / \mathrm{s}$, (b) $14.64 \mathrm{~mm} / \mathrm{s}$, and (c) $21.96 \mathrm{~mm} / \mathrm{sec}$. Laser power is constant $(150 \mathrm{~W})$.

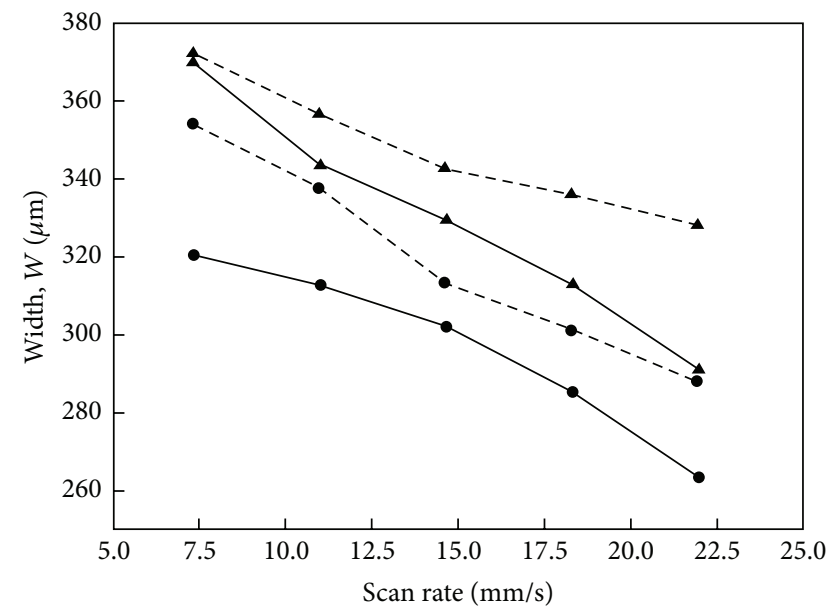

$-\bullet-\operatorname{Ar} 150 \mathrm{~W}$

Water $150 \mathrm{~W}$
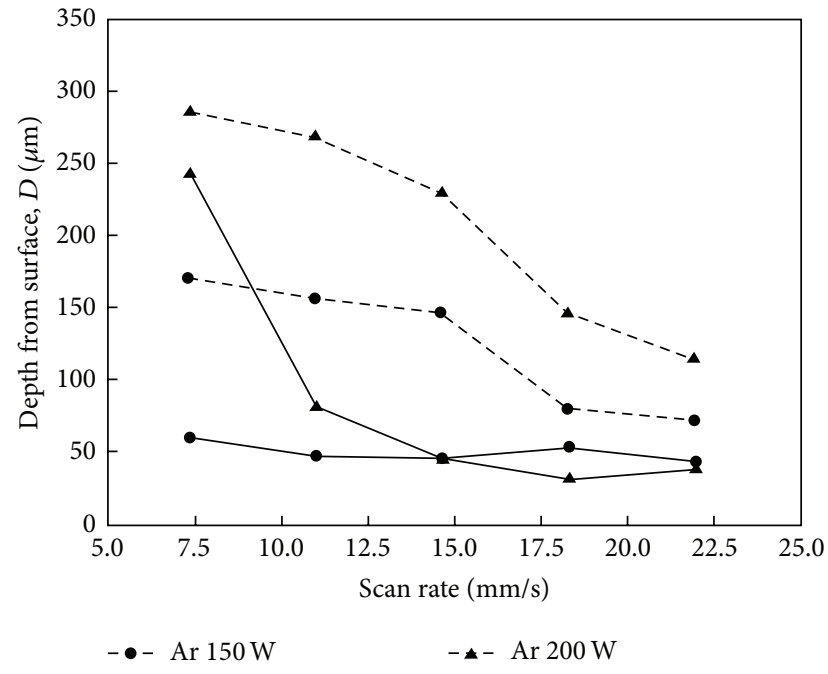

$\rightarrow$ Water $150 \mathrm{~W}$

- $-\operatorname{Ar} 200 \mathrm{~W}$

$\rightarrow$ Water $200 \mathrm{~W}$

(a)

(b)

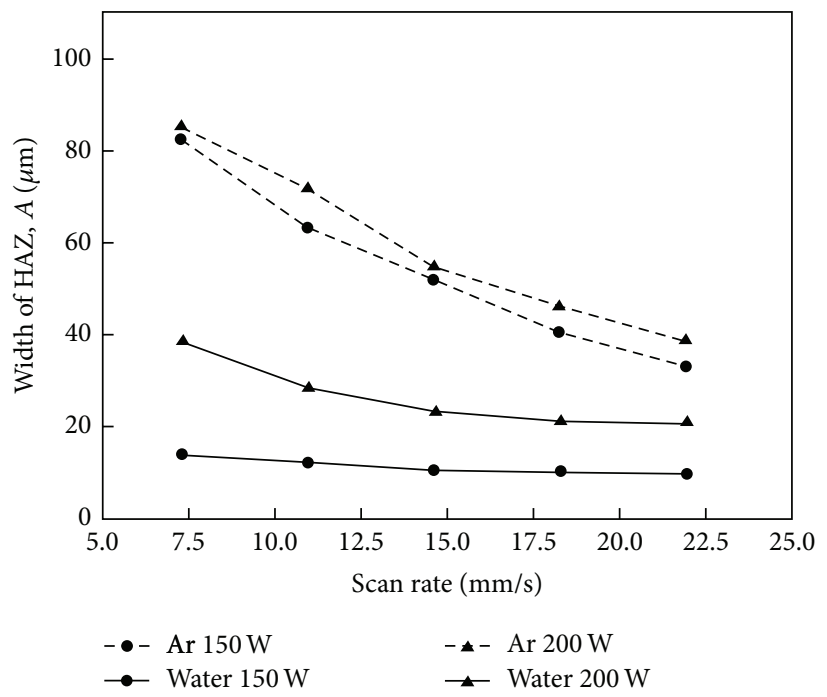

(c)

Figure 7: Comparisons of laser scan rate effects on (a) deposition width, (b) depth from surface, and (c) HAZ width. 


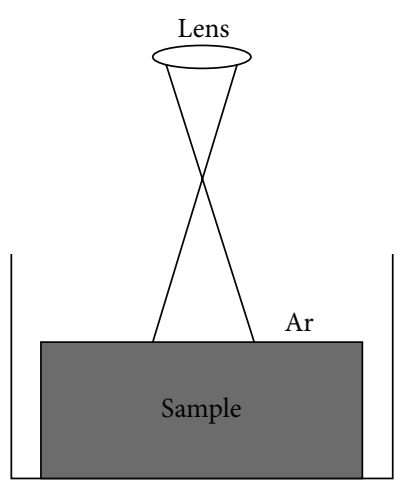

(a)

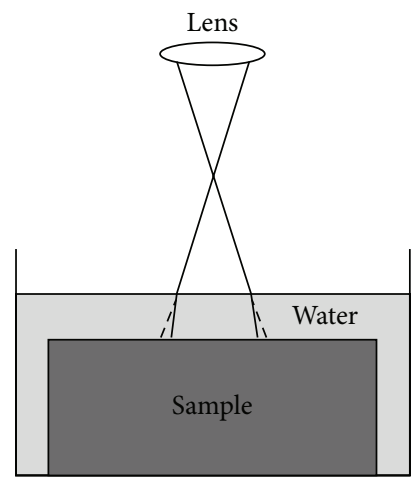

(b)

FIGURE 8: Schematic drawings of (a) straight beam at Ar environment and (b) refracted beam in underwater condition.

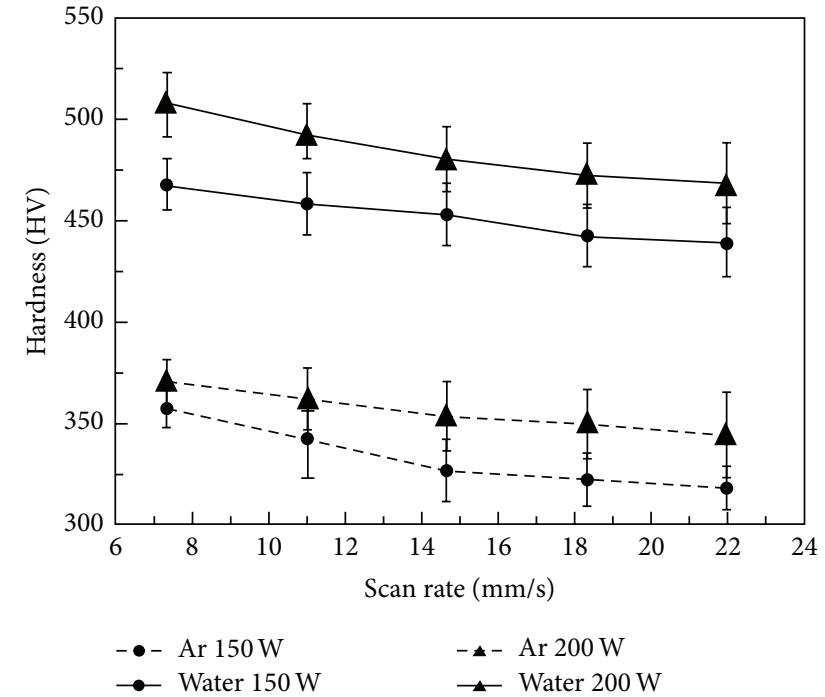

FIGURE 9: Comparisons of laser scan rate effects on microhardness of laser hardened beads.

As the higher heat input (i.e., high laser power and lower scan rate) provides more energy, the temperature of the molten metal increases. High energy input in laser surface hardening has high possibility of increased melting zone. As shown previously, the shape and size of hardened bead generated by laser hardening process are strongly dependent on 3D heat dissipations from molten pool. While, the hardness of hardened layer is mainly determined by microstructure, the cooling rate of molten pool is very crucial for increased hardness. In case of underwater laser hardening, additional heat dissipation effect along water layer accelerates cooling rate. Therefore the hardness of underwater laser hardened layers shows approximately $30 \%$ higher hardness than those of laser hardened layers at Ar environment.

\section{Conclusions}

The feasibility of underwater laser surface hardening process has been discussed on the basis of hardened bead shape and average hardness level. As the hardened depth depends on the thermal conductivity of the material, the surface temperature and the penetration depth have been varied by underwater laser processing. The shape of hardened bead, such as deposition line width, the penetration depth, and HAZ width are somewhat similar, but the penetration depth and HAZ width are significantly smaller than those of $\mathrm{Ar}$ environment due to the refraction of the beam in water layer and the accelerated heat dissipation along water layer. On the viewpoint of hardness, harder layer has been obtained at underwater hardening that is supposed to be caused by faster cooling rate due to accelerated heat dissipation along water layer.

\section{Conflict of Interests}

The authors declare that there is no conflict of interests regarding the publication of this paper.

\section{Acknowledgments}

This work was supported by the National Research Foundation of Korea (NRF) grant funded by the Korea government (MSIP) (no. 2012R1A5A1048294).

\section{References}

[1] F. Verhaeghe, T. Craeghs, J. Heulens, and L. Pandelaers, "A pragmatic model for selective laser melting with evaporation," Acta Materialia, vol. 57, no. 20, pp. 6006-6012, 2009.

[2] A. Simchi and H. Pohl, "Effects of laser sintering processing parameters on the microstructure and densification of iron powder," Materials Science and Engineering: A, vol. 359, no. 1-2, pp. 119-128, 2003.

[3] J.-H. Lee, J.-H. Jang, B.-D. Joo, H.-S. Yim, and Y.-H. Moon, "Application of direct laser metal tooling for AISI H13 tool steel," Transactions of Nonferrous Metals Society of China, vol. 19, no. 1, pp. s284-s287, 2009.

[4] J.-H. Jang and Y.-H. Moon, "Laser processing technology using metal powders," Journal of Korean Institute of Metals and Materials, vol. 50, no. 3, pp. 191-200, 2012. 
[5] H. Shin, H. Lee, H. Yoo, K.-S. Lim, and M. Lee, "Laserdirect patterning of nanostructured metal thin films," Journal of Korean Institute of Metals and Materials, vol. 48, no. 2, pp. 163-168, 2010.

[6] S. L. Engel, "Basic of laser heat treating," in Source Book on Applications of the Laser in Metalworking, E. A. Metzbower, Ed., p. 149, American Society for Metals, Metals Park, Ohio, USA, 1981.

[7] J. H. Abboud, K. Y. Benyounis, A. G. Olabi, and M. S. J. Hashmi, "Laser surface treatments of iron-based substrates for automotive application," Journal of Materials Processing Technology, vol. 182, no. 1-3, pp. 427-431, 2007.

[8] R. Komanduri and Z. B. Hou, "Thermal analysis of the laser surface transformation hardening process," International Journal of Heat and Mass Transfer, vol. 44, no. 15, pp. 2845-2862, 2001.

[9] I. Yadroitsev, A. Gusarov, I. Yadroitsava, and I. Smurov, "Single track formation in selective laser melting of metal powders," Journal of Materials Processing Technology, vol. 210, no. 12, pp. 1624-1631, 2010.

[10] S. W. Han, B. D. Joo, and Y. H. Moon, "Selective surface hardening by laser melting of alloying powder," Materials Research Innovations, vol. 18, pp. 902-907, 2014.

[11] J.-H. Jang, B.-D. Joo, C. J. Van Tyne, and Y.-H. Moon, "Characterization of deposited layer fabricated by direct laser melting process," Metals and Materials International, vol. 19, no. 3, pp. 497-506, 2013.

[12] H. Shen, M. Ran, J. Hu, and Z. Yao, "An experimental investigation of underwater pulsed laser forming," Optics and Lasers in Engineering, vol. 62, pp. 1-8, 2014.

[13] S. Mullick, Y. K. Madhukar, S. Roy, S. Kumar, D. K. Shukla, and A. K. Nath, "Development and parametric study of a water-jet assisted underwater laser cutting process," International Journal of Machine Tools and Manufacture, vol. 68, pp. 48-55, 2013. 

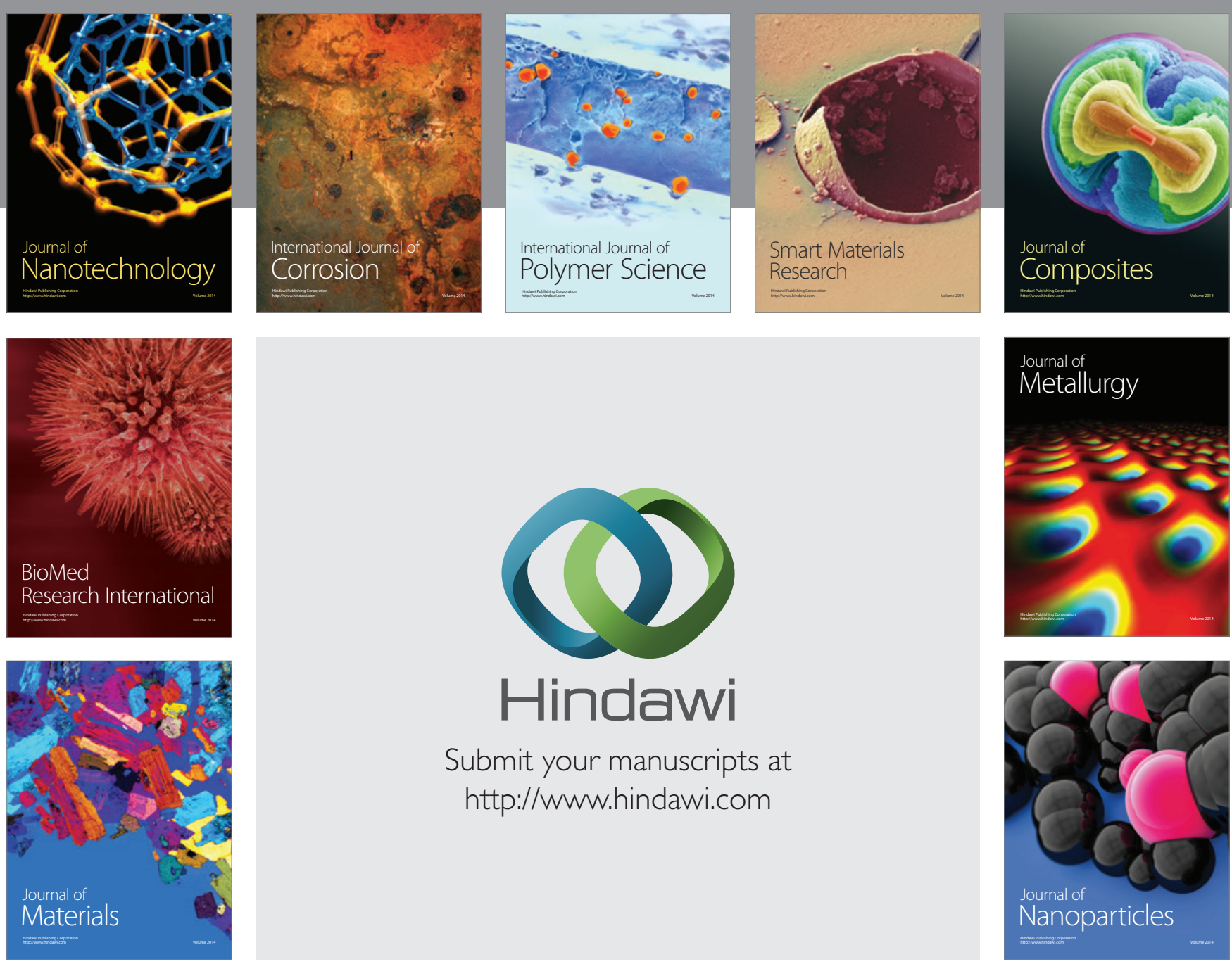

Submit your manuscripts at http://www.hindawi.com
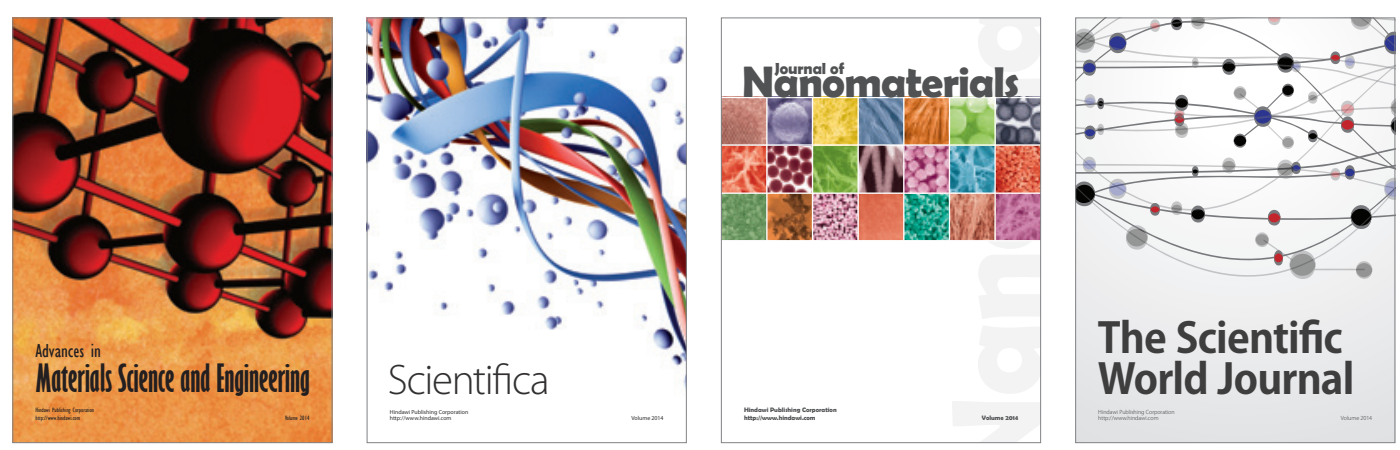

\section{The Scientific World Journal}
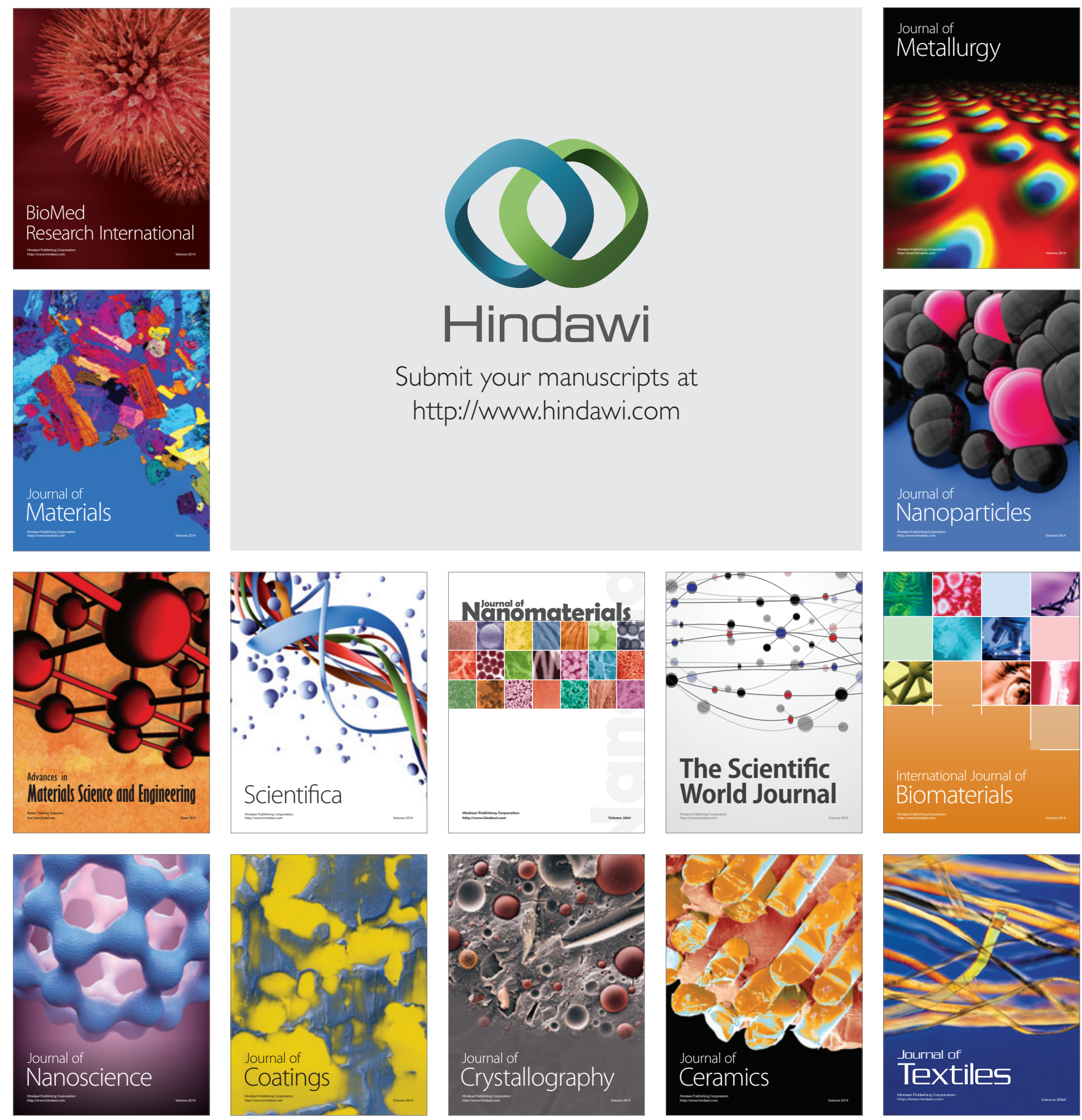